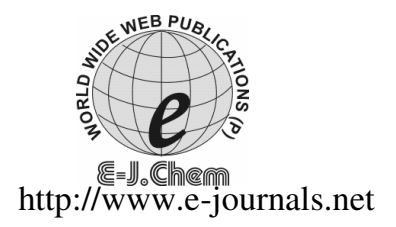

ISSN: 0973-4945; CODEN ECJHAO
E-Journal of Chemistry
2011, 8(1), 347-353

\title{
Impedance Spectroscopy and FTIR Studies of PEG - Based Polymer Electrolytes
}

\author{
ANJI REDDY POLU* and RANVEER KUMAR \\ Solid State Ionics Research Laboratory, Department of Physics \\ Dr. Hari Singh Gour University, Sagar, Madya Pradesh 470003, India \\ reddyphysics06@gmail.com
}

Received 23 May 2010; Accepted 23 July 2010

\begin{abstract}
Ionic conductivity of poly(ethylene glycol) (PEG) - ammonium chloride $\left(\mathrm{NH}_{4} \mathrm{Cl}\right)$ based polymer electrolytes can be enhanced by incorporating ceramic filler $\mathrm{TiO}_{2}$ into $\mathrm{PEG}-\mathrm{NH}_{4} \mathrm{Cl}$ matrix. The electrolyte samples were prepared by solution casting technique. FTIR studies indicates that the complex formation between the polymer, salt and ceramic filler. The ionic conductivity was measured using impedance spectroscopy technique. It was observed that the conductivity of the electrolyte varies with $\mathrm{TiO}_{2}$ concentration and temperature. The highest room temperature conductivity of the electrolyte of $7.72 \times 10^{-6} \mathrm{~S} \mathrm{~cm}^{-1}$ was obtained at $15 \%$ by weight of $\mathrm{TiO}_{2}$ and that without $\mathrm{TiO}_{2}$ filler was found to be $9.58 \times 10^{-7} \mathrm{~S} \mathrm{~cm}^{-1}$. The conductivity has been improved by 8 times when the $\mathrm{TiO}_{2}$ filler was introduced into the $\mathrm{PEG}-\mathrm{NH}_{4} \mathrm{Cl}$ electrolyte system. The conductance spectra shows two distinct regions: a dc plateau and a dispersive region. The temperature dependence of the conductivity of the polymer electrolytes seems to obey the VTF relation. The conductivity values of the polymer electrolytes were reported and the results were discussed. The imaginary part of dielectric constant $\left(\varepsilon_{\mathrm{i}}\right)$ decreases with increase in frequency in the low frequency region whereas frequency independent behavior is observed in the high frequency region.
\end{abstract}

Keywords: Polymer electrolytes, Impedance spectroscopy, FTIR, Ceramic filler, Conductivity.

\section{Introduction}

Polymer electrolytes have been considered as attractive electrolyte material for different electrochemical applications in the past decade on account of certain distinctive properties like ease of fabrication, mouldability into any shape and size good electrode-electrolyte contact, etc ${ }^{1}$. Interest in solid proton-conducting polymer electrolytes started with the development of perfluorinated sulfonic membranes in the $1960 \mathrm{~s}^{2}$. Since then, a lot of work has been developed on proton-conducting polymer electrolytes ${ }^{3-6}$. One promising candidate 
to act as polymer host for proton-conducting polymer electrolyte is $\mathrm{PEG}^{7-8}$. To enhance the conductivity, several approaches were suggested in the literature, including the use of blend polymers, the addition of a ceramic filler, plasticizer and even radiation. Compared to other methods, the addition of a ceramic filler is the simplest and most effective way to improve the conductivity of a solid polymer electrolytes (SPEs). The variation of ionic conductivity with salt fraction is an interesting but difficult challenge for both experimental and theoretical research. Most studies have been on high molecular weight [e.g., PEO, with mol wt. $\sim 10^{6}$ ] polymers complexed with alkali metal salts. Little attention has been paid to the somewhat low molecular weight polymers. Bearing these facts in mind, we have prepared poly (ethylene) glycol (PEG) of molecular weight 4000, complexed with $\mathrm{NH}_{4} \mathrm{Cl}$ salt.

In this work, we report the composite solid polymer electrolytes prepared by the addition of $\mathrm{TiO}_{2}$ particles to $\mathrm{PEG}-\mathrm{NH}_{4} \mathrm{Cl}$. The purpose of this work is to emphasis the extraordinary effect occurring in the PEG- $\mathrm{NH}_{4} \mathrm{Cl}-\mathrm{TiO}_{2}$ composite polymer electrolytes. Our results demonstrate that the dispersion of $\mathrm{TiO}_{2}$ particles in the $\mathrm{PEG}-\mathrm{NH}_{4} \mathrm{Cl}$ matrix leads to an increase in the ionic conductivity of the composite polymer electrolytes without introducing any liquid phase. These composite polymer electrolytes have been characterized using Fourier transform infrared spectroscopy (FTIR) and impedance spectroscopic techniques.

\section{Experimental}

PEG (average molecular weight 4,000) purchased from $\mathrm{CDH}$, India, was dried at $45^{\circ} \mathrm{C}$ for $5 \mathrm{~h}$; $\mathrm{NH}_{4} \mathrm{Cl}\left(\mathrm{CDH}\right.$, India) was dried at $50{ }^{\circ} \mathrm{C}$ for $24 \mathrm{~h}$ and $\mathrm{TiO}_{2}$ procured from Aldrich, USA of particle size $<5 \mu \mathrm{m}$ was used after annealing at $100{ }^{\circ} \mathrm{C}$ for $10 \mathrm{~h}$. Solid polymer electrolyte samples were prepared using the solution cast technique. PEG (molecular weight of 4,000) was used as the polymer. $\mathrm{NH}_{4} \mathrm{Cl}$ was added accordingly. The solvent used in this work is distilled water. The mixture was stirred up to $10 \mathrm{~h}$ to obtain a homogeneous solution. After incorporating the required amount of inorganic filler $\left(\mathrm{TiO}_{2}\right.$ powder) was suspended in the solution and stirred for about $10 \mathrm{~h}$. The solution was then poured into the glass petri dishes and evaporated slowly at room temperature under vaccum. The polymer electrolyte samples were then transferred into a desiccator for further drying before the test.

When the polymer electrolytes have formed they were placed between the blocking stainless steel electrodes of the conductivity cell with leads connected to a HIOKI 3532-50 LCR meter interfaced to a computer for conductivity measurements. The measurements were made over a frequency range of $50 \mathrm{~Hz}$ to $5 \mathrm{MHz}$ at different temperatures. The conductivity $\sigma$ and imaginary part of complex dielectric constant $\left(\varepsilon_{\mathrm{i}}\right)$ of the samples were determined using the standard relations:

$$
\begin{aligned}
\sigma & =\mathrm{d} / \mathrm{RA} \\
\varepsilon_{\mathrm{i}} & =\mathrm{Z}^{\prime} / \omega \mathrm{C}_{0}\left[Z^{\prime 2}+Z^{\prime 2}\right]
\end{aligned}
$$

Here $A$ is the electrode area, $d$ is the thickness of the sample, $R$ is the bulk resistance and $\omega=2 \pi f$. $f$ being the frequency in Hertz. The temperature dependent conductivity studies were carried out for PEG- $\mathrm{NH}_{4} \mathrm{Cl}-\mathrm{x}$ wt $\% \mathrm{TiO}_{2}(\mathrm{x}=0,5,10,15,20)$ polymer electrolytes. Conductivity measurements were carried out over the same frequency range for temperatures ranging from laboratory temperature to $333 \mathrm{~K}$. The conductivity cell with connecting lead wires were placed in an oven with temperature control facilities.

Infrared spectra profiles were obtained using SHIMADZU-8000 Fourier transform infrared (FTIR) spectrophotometer in the range $400-4,000 \mathrm{~cm}^{-1}$ in the transmittance mode at room temperature. 


\section{Results and Discussion}

\section{FTIR analysis}

FTIR spectroscopy is important for the investigation of polymer structure. Since, it provides information about the complexation and interactions between the various constituents in the polymer electrolyte. These interactions can induce changes in the vibrational modes of the molecules in the polymer electrolyte. The FTIR spectra of PEG, PEG: $\mathrm{NH}_{4} \mathrm{Cl}$ and PEG: $\mathrm{NH}_{4} \mathrm{Cl}+\mathrm{x}$ wt $\% \mathrm{TiO}_{2}(\mathrm{x}=5,10,15)$ are shown in Figure 1.

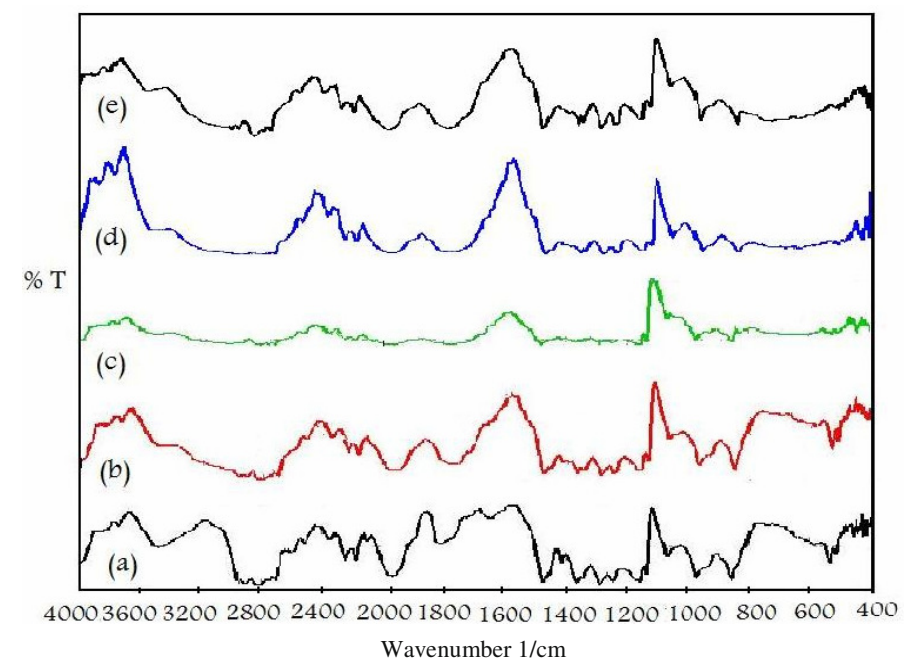

Figure 1. FTIR spectra of pure (a) PEG and complexes PEG-NH4Cl-X \% TiO2; (b) 0\%; (c) $5 \%$; (d) $10 \%$; (e) $15 \%$

The Polyethylene glycol exhibits absorptions those of a primary alcohol. Hence these absorptions, which comprise stretching and bending vibrations restricted to $\mathrm{C}-\mathrm{C}$ stretch, $\mathrm{C}-\mathrm{O}$ stretch, $\mathrm{CH}$ stretch (methylene absorptions) and the $\mathrm{C}-\mathrm{H}$ bending. The $\mathrm{OH}$ stretching vibration is observed in the region $3378 \mathrm{~cm}^{-1}$ exhibiting hydrogen bonded nature. The same absorption is not observed in any polymer complexes. This clearly indicates that the influence of $\mathrm{NH}_{4} \mathrm{Cl}$ does affect the absorption of the respective functional groups. The methylene group found in PEG has been found to vibrate in the stretching mode around $2803 \mathrm{~cm}^{-1}$. The absorption around $1474 \mathrm{~cm}^{-1}$ is due to binding vibration of $-\mathrm{CH} 2$. As in the case of primary alcohol, the $\mathrm{C}-\mathrm{O}$ stretching vibration, a strong band around $1362 \mathrm{~cm}^{-1}$ and $1287 \mathrm{~cm}^{-1}$ is also observed. A similar vibration is exhibited by pure PEG and PEG: $\mathrm{NH}_{4} \mathrm{Cl}$ complexes. A sharp - strong band at $966 \mathrm{~cm}^{-1}$ and $849 \mathrm{~cm}^{-1}$ is due to the C-C stretching.

The group frequencies at 3,268, 2,095, 1,790, 1,044 and $835 \mathrm{~cm}^{-1}$ of PEG are found absent in all the complexes and some new peaks at 2,592, 2,425, 2,357, 1,973, 812 and $636 \mathrm{~cm}^{-1}$ are found present. The above analysis establishes the formation of the polymer-salt-filler complex.

\section{Impedance analysis}

Figure 2 represents the complex impedance spectrum/ Nyquist plot ( $Z^{\prime \prime}$ vs. $Z^{\prime}$ ) of composite polymer electrolytes of $\mathrm{PEG}-\mathrm{NH}_{4} \mathrm{Cl}+x$ wt $\%$ of $\mathrm{TiO}_{2}$ for various ceramic filler concentrations $(x)$ at room temperature. 


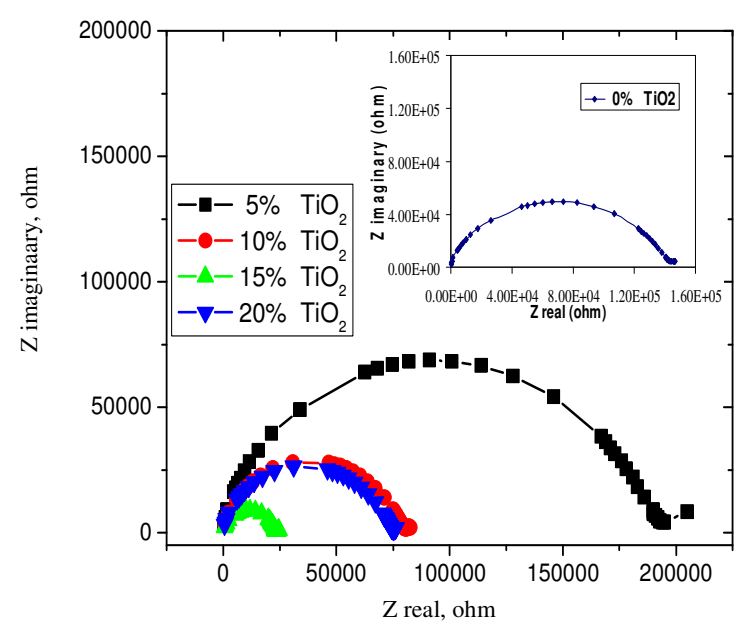

Figur 2. Variation of imaginary $\left(Z^{\prime \prime}\right)$ with real $\left(Z^{\prime}\right)$ part of impedance of $\mathrm{PEG}-\mathrm{NH}_{4} \mathrm{Cl}+x$ wt $\%$ of $\mathrm{TiO}_{2}$ with different concentrations $(x)$ of $\mathrm{TiO}_{2}$ at room temperature $\left(30{ }^{\circ} \mathrm{C}\right)$

The typical Nyquist plot of the samples comprises of a broadened semicircle in the high frequency region followed by a tail (spike) in the lower frequency region (in some plots). The higher frequency semicircle can be ascribed mainly to the bulk properties of the materials, where as the low frequency spike indicates the presence of double layer capacitance at the electrode/sample interface ${ }^{9}$. The intercept of the semicircle with the real axis $\left(Z^{\prime}\right)$ at low frequency (end) give rise to the bulk (ionic) resistance $\left(R_{b}\right)$ of the materials. By knowing the value of bulk resistance along with the dimensions of the sample, the ionic conductivity has been calculated and has been given in Table 1 .

Table 1. Ac conductivity values of $\mathrm{PEG}-\mathrm{NH}_{4} \mathrm{Cl}+x$ wt $\%$ of $\mathrm{TiO}_{2}(\mathrm{x}=0,5,10,15,20)$ at $303 \mathrm{~K}$

\begin{tabular}{cc}
\hline Sample & Conductivity $\sigma_{\mathrm{b}}$ at $303 \mathrm{~K}, \mathrm{~S} / \mathrm{cm}$ \\
\hline $85-15-00$ & $9.58 \mathrm{E}-07$ \\
$85-15-05$ & $1.50 \mathrm{E}-06$ \\
$85-15-10$ & $3.59 \mathrm{E}-06$ \\
$85-15-15$ & $7.72 \mathrm{E}-06$ \\
$85-15-20$ & $4.27 \mathrm{E}-06$ \\
\hline
\end{tabular}

\section{Temperature dependent ionic conductivity}

The temperature dependence of electrical conductivity of the polymer samples is shown in Figure 3. The non- linearity in the plot indicates that the ion transport in polymer electrolytes is dependent on polymer segmental motion ${ }^{10}$.

Thus the result may be more effectively represented by the Vogel-Tamman- Fulcher (VTF) equation

$$
\sigma=\mathrm{AT}^{-1 / 2} \exp \left[-\mathrm{E}_{\mathrm{a}} / \mathrm{K}\left(\mathrm{T}_{0}-\mathrm{T}_{\mathrm{g}}\right)\right]
$$

Where A-fitting constant proportional to the number of charge carriers. $\mathrm{E}_{\mathrm{a}}$-pseudo activation energy, K-Boltzmann constant and $\mathrm{T}_{0}$-equilibrium temperature of the system corresponding to zero configuration entropy. Tg-the thermodynamic glass transition temperature of the system.

Figure 4 shows the variation of conductivity with $\mathrm{TiO}_{2}$ concentration for different temperatures. The enhancement in the ionic conductivity with the increasing concentration of $\mathrm{TiO}_{2}$ may be due to $\mathrm{TiO}_{2}$ which interacts with either of both the anion and cation thereby reducing ion pairing and increases the free charge carriers. The same type of behaviour has been 
reported in $\mathrm{Al}_{2} \mathrm{O}_{3}$ dispersed PEO-LiTFSI based polymer composites ${ }^{11}$. A further increment in $\mathrm{TiO}_{2}$ concentrations results in a decrease in conductivity which may be due to the restricted ionic and polymer segmental mobility in a rigid matrix at room temperature. As the temperature increases the charge carries are thermally activated and the free volume increases and more vacant sites are created for the motion of ions, which in turn enhances the conductivity.

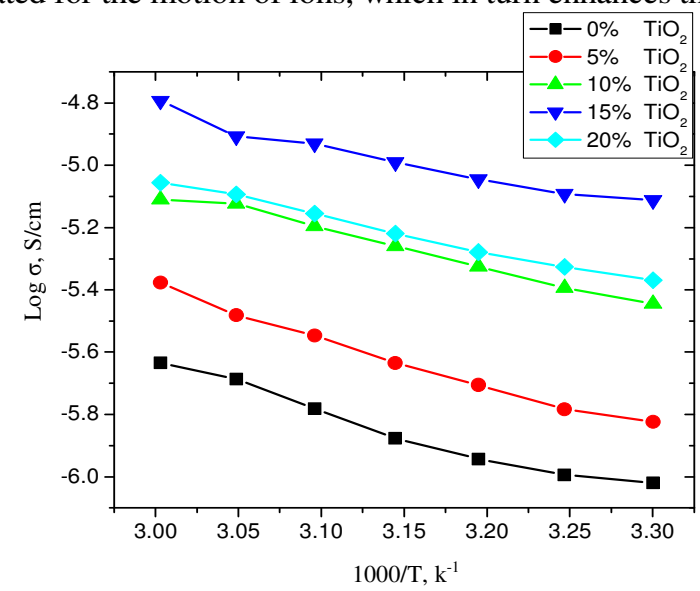

Figure 3. Temperature dependent ionic conductivity for all samples

\section{AC Conductivity analysis}

The variation of the ac conductivity with frequency for different $\mathrm{TiO}_{2}$ concentration with polymer electrolytes at $303 \mathrm{~K}$ is shown in Figure 5. The frequency dependent ac conductivity of the polymer electrolyte is described by almond and west formalism ${ }^{12}$,

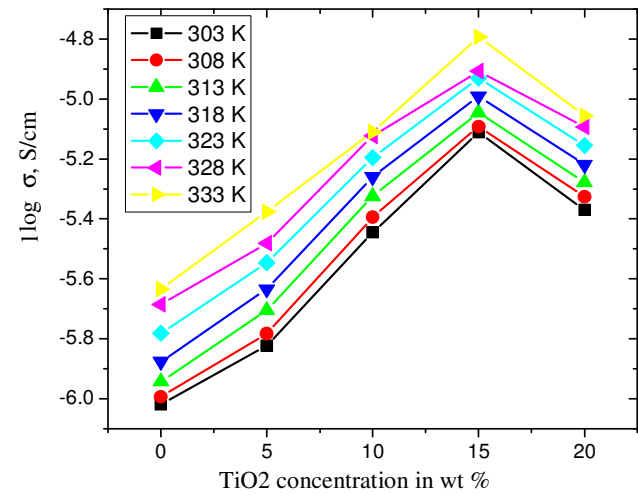

Figure 4. Dependence of ionic conductivity on filler concentration for $\mathrm{PEG}-\mathrm{NH}_{4} \mathrm{Cl}$ polymer complex at different temperatures

$$
\sigma(\omega)=\sigma_{\mathrm{dc}}+\mathrm{A} \omega^{\mathrm{n}}
$$

Where $A$ and $n$ are material parameters, $0<n<1, \sigma_{\mathrm{dc}}$ is dc ionic conductivity and $\omega$ is the angular frequency. The plot shows two regions: The first one is the low frequency dispersion region observed which can be ascribed to the space charge polarization at the blocking electrodes. The second region corresponds to the frequency independent plateau region. 
The conductivity is found almost frequency independent in this region and the extrapolation of the plot to $y$-axis gives the value of dc conductivity for all samples. From the plot it is observed that the dc conductivity increases from $9.36 \times 10^{-7} \mathrm{~S} / \mathrm{cm}$ to $7.42 \times 10^{-6} \mathrm{~S} / \mathrm{cm}$ with increase of $\mathrm{TiO}_{2}$ concentration up to $15 \mathrm{wt} \%$ and after which the conductivity decreases which is in good agreement with the impedance analysis. The possible decrease in the ionic conductivity at $20 \mathrm{wt}$ $\% \mathrm{TiO}_{2}$ can be attributed to the restricted motion of ions in the rigid polymer matrix.

\section{Dielectric studies}

The frequency dependence of the imaginary part of dielectric constant curve for all samples at room temperature $(303 \mathrm{~K})$ is shown in Figure6. The imaginary part of dielectric constant decreases with increase of frequency and it gets saturated at higher frequencies. The high value of dielectric constant at low frequencies can be attributed to the accumulation of charge carriers near the electrodes ${ }^{13}$. The higher values of dielectric constant for $15 \mathrm{wt} \% \mathrm{TiO}_{2}$ (higher conductivity) is due to the enhanced charge carrier density at the space charge accumulation region, resulting in a rise in the equivalent capacitance. At higher frequencies, the dielectric constant decreases due to the high periodic reversal of the applied field.

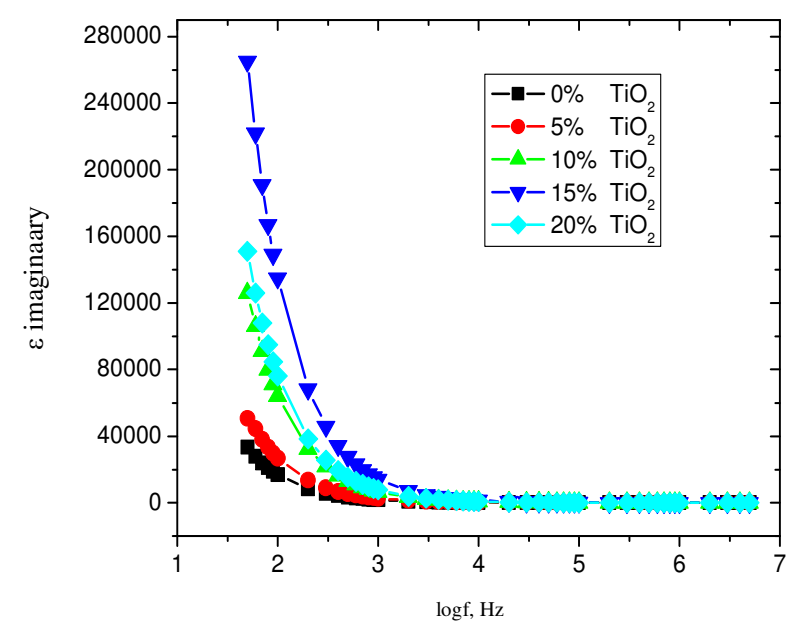

\section{Conclusion}

Figure 6. Variation of $\varepsilon_{\text {imaginary }} v s$. $\operatorname{logf}$ at $303 \mathrm{~K}$

The composite polymer electrolytes have been prepared by solution casting technique. From the FTIR analysis it is evident that there exits complex formation among polymer, ammonium salt and $\mathrm{TiO}_{2}$. From the impedance analysis it has been found that the high ionic conductivity of $7.72 \times 10^{-6} \mathrm{Scm}^{-1}$ at $303 \mathrm{~K}$ is obtained for the composite with $15 \mathrm{wt} \%$ $\mathrm{TiO}_{2}$. This enhancement in conductivity is due to the dispersion of $\mathrm{TiO}_{2}$ filler which creates free pathways for the ions to move. The temperature dependence of the conductivity of the polymer electrolytes seems to obey the VTF relation. The imaginary part of dielectric constant $\left(\varepsilon_{\mathrm{i}}\right)$ decreases with increase in frequency in the low frequency region whereas frequency independent behavior is observed in the high frequency region.

\section{References}

1 Gray F M, Solid Polymer Electrolytes: Fundamentals and Technological Applications, VCH, New York, 1991. 
2 Bozkurt A and Meyer W H, Solid State Ionics, 2001, 138, 259-265.

3 Stevens J R, Wieczorek W, Raducha D and Jeffrey K K, Solid State Ionics, 1997, 97(1-4), 347-358.

4 Asensio J A, Borros S and Gomez-Romero P, J Membr Sci., 2004, 241(1), 89-93.

5 Qu X, Wirse'n A and Albertsson A C, Polymer, 2000, 41, 4841-4847.

6 Khalid M N, Agnely F, Yagoubi N, Grossiord J L and Couarraze G, Eur J Pharm., Sci., 2002, 15(5), 425-432.

7 Nader Binesh and Bhat S V, Solid State Ionics, 1999, 122(1-4), 291-299.

$8 \quad$ Nader Binesh and Bhat S V, Solid State Ionics, 1996, 92, 261.

9 Macdonald J R, Impedance spectroscopy, Emphasizing Solid Materials and Systems. Wiley, New York 1987.

10 Okamoto Y, Yeh T F, Lee H. S and Skotheimk T A, J Polym Sci A: Poly Chem., 1993, 31, 2573.

11 Jayathilaka P A R D, Dissanayake M A K L, Albinsson I and Mellander B E, Electrochimica Acta., 2002, 47(20), 3257-3568.

12 Almond D P and West A R, Solid State Ionics, 1987, 23, 27.

13 Armstrong R D, Dickinson T D and Willis P M, Electroanal Chem Interfacial Electrochem., 1974, 53, 389. 


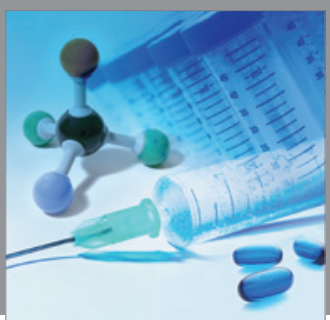

International Journal of

Medicinal Chemistry

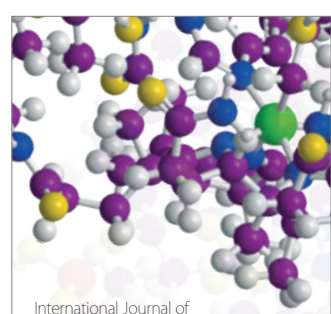

Carbohydrate Chemistry

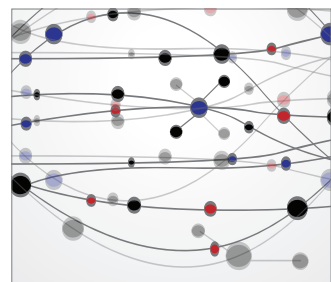

The Scientific World Journal
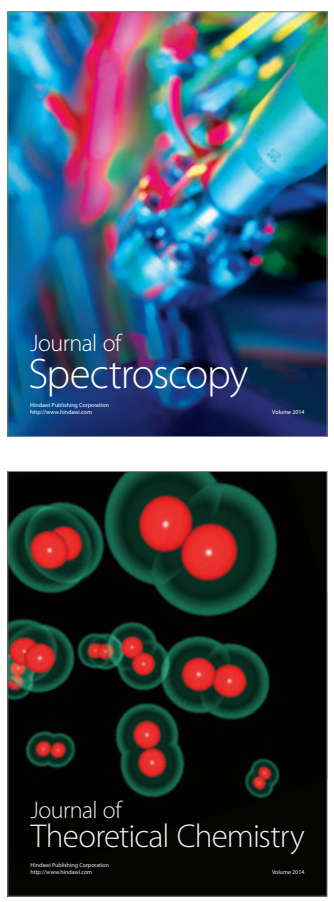
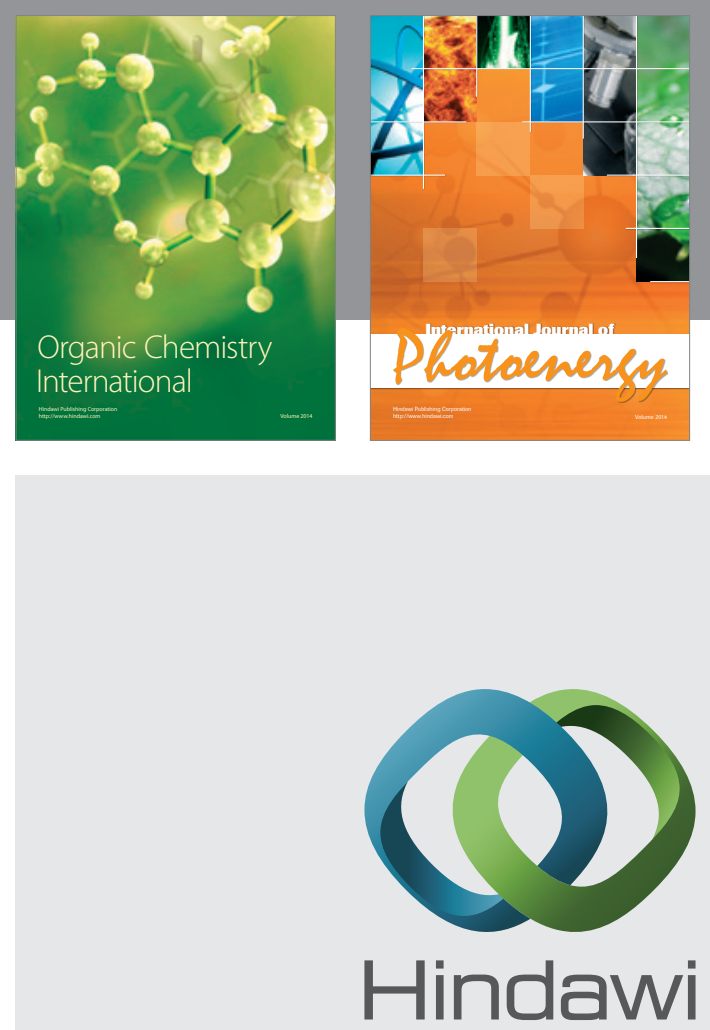

Submit your manuscripts at

http://www.hindawi.com
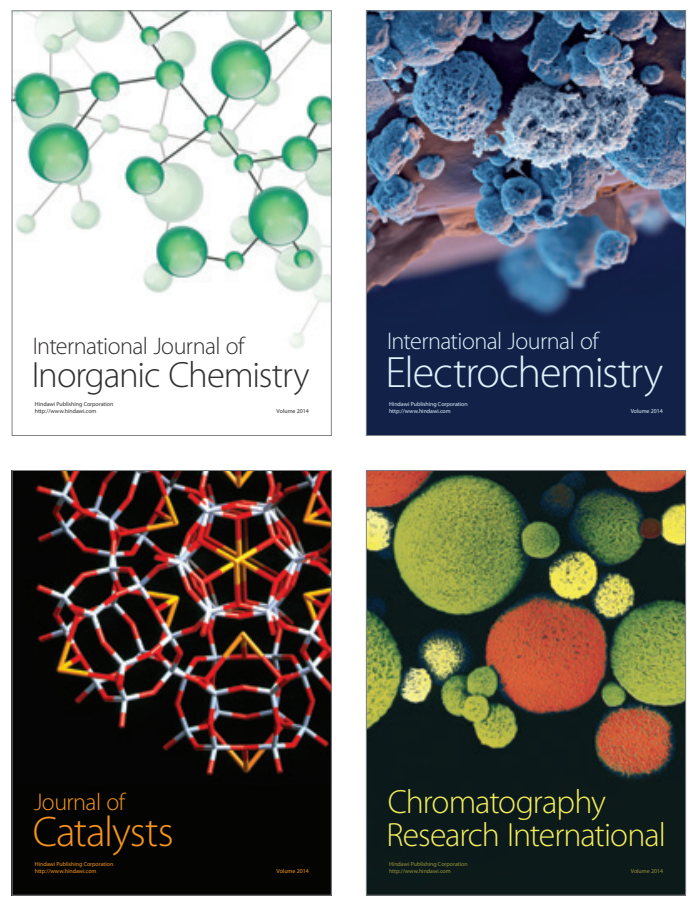
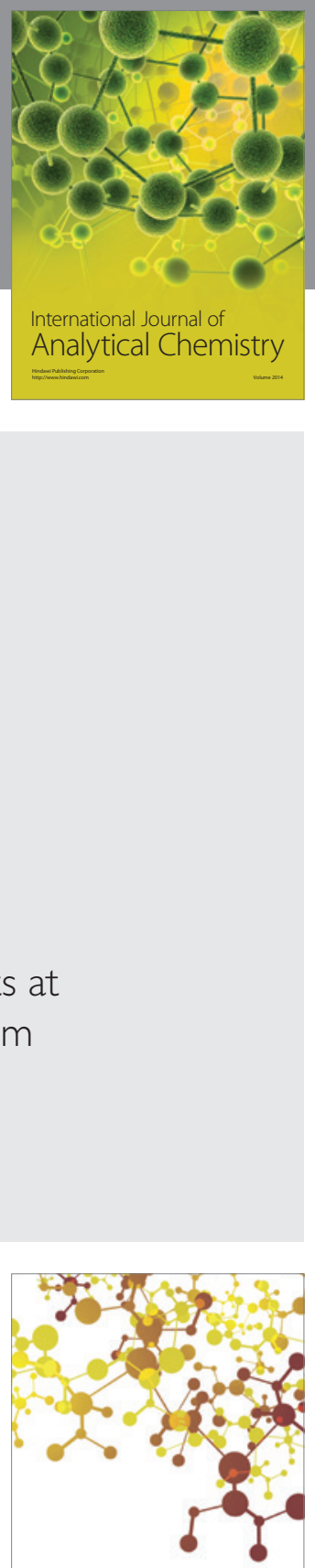

Journal of

Applied Chemistry
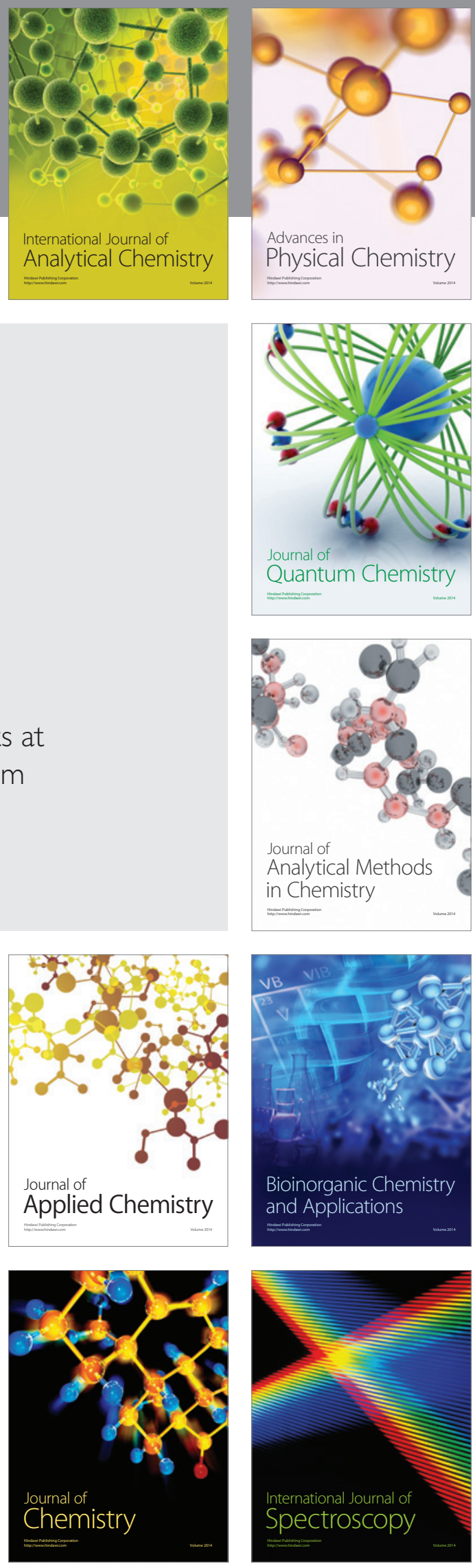